\title{
Cine 3D español: experiencias del cine estereoscópico 3D durante los años del franquismo
}

\section{José Patricio Pérez-Rufí1 Juan Ángel Jódar-Marín²}

Recibido: 16/04/2018

Aprobado por pares: 17/10/2018
Enviado a pares: 03/05/2018

Aceptado: 24/10/2018

DOI: 10.5294/pacla.2019.22.3.2

Para citar este artículo / to reference this article / para citar este artigo

Pérez-Rufí, J. P. y Jódar-Marín, J. Á. (2019). Cine 3D español: experiencias del cine estereoscópico 3D durante los años del franquismo. Palabra Clave, 22(3), e2232.

DOI: http://doi.org/10.5294/pacla.2019.22.3.2

\section{Resumen}

Este artículo investiga los orígenes de la producción española en cine estereoscópico 3D en la década de los cincuenta y sesenta, en pleno franquismo. La rapidez en la producción de cortometrajes tridimensionales muestra un conocimiento de la tecnología de producción foránea y una enorme flexibilidad y agilidad a la hora de crear contenidos 3D en España. El objetivo principal de esta investigación es identificar aquellas producciones cinematográficas españolas realizadas con técnicas estereoscópicas desde la propia filmación o tras su adecuación con técnicas de posproducción para la proyección. La hipótesis es que las muestras puntuales que ha dado la cinematografía española de cintas tridimensionales han respondido a fenómenos de moda pasajeros y no han supuesto hitos de importancia comercial o artística, más allá de la experimentación con las posibilidades del formato. Con todo, recogen una voluntad de aperturismo del cine español hacia las nuevas tecnologías y hacia la búsqueda del público. Aplicaremos una metodología basada en el estudio de caso,

1 orcid.org/0000-0002-7084-3279. Universidad de Málaga, España. patricioperez@uma.es

2 orcid.org/0000-0003-0861-1124. Universidad de Granada, España. jajodar@ugr.es 
a partir de la revisión bibliográfica de fuentes primarias y secundarias dedicadas a la producción y la exhibición cinematográfica en España. Los resultados muestran que la influencia de la cinematografía estadounidense en su vertiente más tecnológica y comercial es evidente, incluso si los organismos del Régimen aplican políticas proteccionistas agresivas frente a la importación de filmes estadounidenses. La conflictiva relación de las productoras de Hollywood con el Régimen franquista no impide su liderazgo en la recaudación en la taquilla ni su influencia en los modos de producción de la cinematografía nacional.

\section{Palabras clave (Fuente: tesauro de la Unesco)}

Cine; cine español; historia del cine; cine estereoscópico 3D; cine 3D; tecnología audiovisual; posproducción audiovisual. 


\section{Spanish 3D Cinema: 3D Stereoscopic Filmmaking Experiences During Franco's Regime}

\section{Abstract}

This article studies the origins of Spanish 3D stereoscopic filmmaking in the 1950s and 1960s, in the middle of the Francoist regime. The speed with which three-dimensional short films were made suggests knowledge of foreign production technology and enormous flexibility and agility when creating 3D contents in Spain. The main objective of this research is to identify those Spanish films produced using stereoscopic techniques from the shooting itself or after their adaptation with post-production techniques for screening. The hypothesis is that the specific specimens of three-dimensional films supplied by Spanish cinema have responded to transient trends and have not meant commercially or artistically significant milestones, beyond experimentation with the possibilities of the format. However, they reflect Spanish cinema's willingness to open to innovative technologies and to reach the audience. We applied a case study-based method from the bibliographic review of primary and secondary sources dedicated to film production and exhibition in Spain. Results show that the influence of American cinema in its most technological and commercial aspects is evident, even when the regime's bodies operated aggressive protectionist policies against the import of American films. The conflictive relationship between Hollywood producers and Francoism did not prevent their box-office success nor their influence on the production modes of national cinema.

\section{Keywords (Source: Unesco Thesaurus)}

Cinema; spanish cinema; history of cinema; 3D stereoscopy; 3D film; audiovisual technology; audiovisual post-production. 


\section{Cinema 3D espanhol: experiências do cinema estereoscópico 3D durante os anos do franquismo}

\section{Resumo}

Este artigo pesquisa sobre as origens da produção espanhola no cinema estereoscópico 3D na década dos 1950 e 1960, em pleno franquismo. A rapidez na produção de curtas-metragens tridimensionais mostra um conhecimento da tecnologia de produção estrangeira e uma enorme flexibilidade e agilidade no momento de criar conteúdo 3D na Espanha. O objetivo principal desta pesquisa é identificar as produções cinematográficas espanholas realizadas com técnicas estereoscópicas desde a própria filmagem ou após a sua adequação com técnicas de pós-produção para a projeção. A hipótese é que as amostras pontuais que a cinematografia espanhola deu de fitas tridimensionais responde a fenômenos de moda passageiros e não são marcos de importância comercial ou artística, mais além da experimentação com formatos. Contudo, demonstram uma vontade de abertura do cinema espanhol às novas tecnologias e à busca do público. Aplicamos uma metodologia baseada no estudo de caso, a partir da revisão bibliográfica de fontes primárias e secundárias dedicadas à produção e à exibição cinematográfica na Espanha. Os resultados mostram que a influência da cinematografia estadunidense em sua vertente mais tecnológica e comercial é evidente, inclusive se os organismos do Regime aplicam políticas protecionistas agressivas diante da importação de filmes estadunidenses. A conflitiva relação das produtoras de Hollywood com o Regime franquista não impede sua liderança na bilheteria nem sua influência nos modos de produção da cinematografia nacional.

\section{Palavras-chave (Fonte: tesauro da Unesco)}

Cinema; cinema espanhol; história do cinema; cinema estereoscópico 3D; cinema 3D; tecnologia audiovisual; pós-produção audiovisual. 


\section{Introducción}

El estudio de la producción cinematográfica española en formatos estereoscópicos supone un campo de investigación inexplorado por su singularidad, que proporciona, con todo, sorpresas notables: la limitada difusión que lograron estas piezas, así como la escasa información disponible acerca del uso de las tecnologías $3 \mathrm{D}$ en la producción nacional convierten a aquellas en rarezas prácticamente desconocidas tanto por investigadores como por cinéfilos. Como filmografía más bien reducida, con un número muy limitado de películas, la propia identificación de los títulos de las obras filmadas en técnicas tridimensionales requiere un proceso de investigación para el que no siempre encontraremos respuestas ni nos llevará a conclusiones contrastadas. Apunta Russo (2012, p. 270) que el cine 3D "quedó relegado a un episodio breve pero intenso en la historia del cine comercial de gran espectáculo, y sus anteojos se convirtieron en memorabilia", añadiendo que su historia es mucho más prolongada e intrincada, "revelando algo más que su empeño por ampliar los efectos de asombro y fascinación provistos en pantalla".

En esta línea, esta investigación pretende explorar los orígenes de la producción española en cine estereoscópico en las décadas de los cincuenta y sesenta, dentro de lo que hemos considerado dos fases de experimentación en los sistemas de filmación y proyección estereoscópicos. Limitamos el seguimiento de las experiencias en 3D hasta finales de la década de los sesenta debido a que no encontraremos más muestras hasta 1981, ya en un contexto histórico, político, social y cultural para la industria cinematográfica completamente diferente del de la década de los cincuenta y los sesenta. Aunque no analizaremos los títulos en 3D desde una óptica ideológica, política o social, la historiografía cinematográfica ha comprendido la contundencia del cambio de un régimen dictatorial a uno democrático como para convertirlo en un punto de inflexión de toda la producción cultural, cualquiera que sea su medio o formato. Incluso si el régimen de Franco fue dictatorial y autárquico en sus primeros años, los productores y los directores de cine españoles demostraron estar al tanto de las innovaciones tecnológicas en la producción y exhibición cinematográfica, e intentaron adaptarse a aquellos con agilidad. 
La reactivación desde el cine más comercial de las técnicas de filmación y exhibición tridimensional, motivada por un contexto de crisis general de la industria cinematográfica a comienzos del siglo XXI, puso de actualidad un fenómeno con una tradición tan antigua como la propia historia del cine. Es desde la actualidad comercial y social que ha tenido el cine tridimensional, de la mano de la propia digitalización de las salas de exhibición, que creemos necesaria una revisión de los orígenes y de las primeras experiencias realizadas desde la cinematografía nacional: el uso del eslogan "la primera película española en 3D" para producciones muy recientes, con un indudable objetivo comercial, habría de ser matizado a tenor de los títulos que mencionaremos, creados para ser proyectados según diferentes procedimientos estereoscópicos.

Centraremos de forma prioritaria, en todo caso, nuestra atención en una primera etapa en torno a 1953 y una segunda etapa alrededor de 1968 , en lo que podrían conformar dos momentos diferenciados en cuanto a técnicas y aplicaciones tecnológicas y a sus paralelas experiencias fílmicas. Con posterioridad a 1969, encontramos raras incursiones en los formatos estereoscópicos que vuelven a correr parejos a contextos de supuesto éxito internacional o que se producen para cine o televisión de manera muy puntual.

El objetivo principal de esta investigación es identificar aquellas producciones realizadas con técnicas estereoscópicas desde la propia producción o tras su adecuación con técnicas de posproducción para la proyección. Del mismo modo, intentaremos demostrar la veracidad de informaciones publicadas al respecto, así como, consecuentemente, refutar aquellos casos en los que se ha atribuido una naturaleza tridimensional sin tenerla en realidad. Enunciamos así como hipótesis de este trabajo que las muestras puntuales que ha dado la cinematografía española de cintas tridimensionales han respondido a fenómenos de moda pasajeros y que esta producción ha venido motivada por tendencias lideradas por la cinematografía estadounidense, incluso si las relaciones entre la industria cinematográfica de Hollywood y las autoridades españolas fueron tensas durante la década de los cuarenta y buena parte de la década de los cincuenta. 


\section{Metodología}

A fin de lograr los objetivos propuestos, aplicaremos una metodología basada en el estudio de caso español, a partir de la revisión bibliográfica de los artículos, estudios e informes dedicados a la producción y la exhibición cinematográfica en España. Recurrimos así a referencias bibliográficas, hemerográficas y digitales que nos ponen en contacto con información acerca de las producciones que ocuparán nuestra atención. Los estudios sobre el cine tridimensional han sido muy escasos y han invitado a sus investigadores a una reflexión más próxima a la semiótica y a las particularidades de su lenguaje que a las relacionadas con su origen y evolución. Acudiremos a las puntuales menciones al cine estereoscópico de Bordwell, Staiger y Thompson (1996), así como al referente básico que supone la obra de Sammons (1994), incluso si refutamos algunas de sus afirmaciones. Igual prudencia se impone en la consulta de historia del cine español realizada por Méndez (1965), hoy muy cuestionada pero inevitable antecedente de los estudios historiográficos de la cinematografía nacional. Entre las fuentes primarias, citamos la prensa de la época (en concreto los diarios $A B C$ y La Vanguardia), así como el valiosísimo Anuario del Cine Español 1955-1956 editado por el Sindicato Nacional del Espectáculo (1956), además de la base de datos de películas calificadas del Instituto de la Cinematografía y de las Artes Audiovisuales, dependiente de Ministerio de Cultura y Deporte del Gobierno de España.

La actualidad de la investigación en el área no ofrece contenidos relevantes al objeto de nuestro trabajo, pero citaremos a Izquierdo (2012) y Russo (2012). Justificamos la ausencia de referentes internacionales, más allá de Sammons (1994) y de Witte (2010), desde la ausencia de investigación en la producción española del formato fuera de nuestras fronteras, incluso en las publicaciones de aquellos autores más referenciados en los estudios internacionales del cine estereoscópico.

\section{Resultados}

\section{Primera fase: Ios cortos de 1953}

El primer fenómeno comercial masivo del cine estereoscópico surge desde los Estados Unidos a partir de 1952, con una duración muy breve, que 
será acompañado de otras incursiones en el género en la producción europea e incluso latinoamericana. La cinematografía nacional participaría de forma muy puntual de este auge a través de dos experiencias concretas que impiden hablar de una apropiación de los procesos y desarrollos del artefacto en nuestro país. De forma paralela al resto del mundo, tras poco más de un año de producción y exhibición tridimensional, se abandona o queda restringida a un ámbito muy minoritario de cine de subgénero. Esta podría suponer una primera fase, tras los antecedentes en el campo de la experimentación con la imagen fija tridimensional en el siglo XIX e incluso el cine mudo, que se verá continuada con otras etapas distanciadas en el tiempo y sin una relación de continuidad.

Apuntemos, en todo caso, que el contexto económico, social, político e industrial es tan diferente en España en 1953 al estadounidense que los usos sociales de las innovaciones tecnológicas en materia de producción cinematográfica han de ser por fuerza diversos. Así, hemos de señalar que la apuesta por el cine estereoscópico en la década los cincuenta en los Estados Unidos responde a la necesidad de generar una demanda de consumo de contenidos por parte de la industria hollywoodense a causa del cambio en los hábitos de consumo que provoca el inicio de las emisiones televisivas a finales de la década de los cuarenta. Frente a un receptor televisivo pequeño, en blanco y negro y con una resolución de imagen muy limitada, el cine proyectado reivindica la diferencia de la experiencia de consumo mediante pantallas cada vez más grandes, en formatos panorámicos, sonido de mejor calidad, color y creación de un efecto de tridimensionalidad, en una primera y breve edad de oro del cine 3D.

En España, por el contrario, las emisiones televisivas no se iniciarán hasta 1956 en ámbitos muy limitados, y con una mayor cobertura a partir de la década de los sesenta. Así pues, la motivación para crear una demanda social de consumo en torno al cine tridimensional difiere. Entendemos estos primeros acercamientos de la producción nacional española al cine estereoscópico como resultado del interés de aquellos creadores que pretenden reproducir dinámicas de mercado similares a las estadounidenses y experimentar con las nuevas posibilidades tecnológicas. 
Hemos de apuntar que las relaciones entre las instituciones públicas del régimen en materia de comunicación y cultura y la Motion Picture Association of America (MPAA) fueron extremadamente complejas y tensas desde el final de la guerra civil hasta bien entrada la década de los cincuenta. Así, por una parte, de todas las cinematografías extranjeras, la estadounidense es la triunfante desde el final de la guerra civil hasta la década de los cincuenta (Bosch \& Del Rincón, 1998; Cánovas, 2015; Rosendorf, 2007). Este dominio de la taquilla española se remonta a la década de los veinte, hasta el punto de que León (2006a, p. 304) llega a calificar el mercado nacional de "un mercado cautivo del cine de Hollywood", de forma paralela a otros países europeos: "Las distintas filiales de las majors, establecidas entre 1922 y 1935, controlaban el negocio de la distribución e importación de películas”.

Tras la guerra civil, las instituciones del régimen dictatorial recelan de la importación de filmes estadounidenses por una cuestión ideológica cuyo instrumento más paradigmático es la censura, pero también por un afán proteccionista de la industria cinematográfica nacional. Según Miguel (2000, p. 65), se trataría de extender también en el cine una política intervencionista con "un dirigismo absoluto del país que se manifiesta a través de medidas tanto represivas como claramente proteccionistas".

Paradójicamente, y frente a esta voluntad aislacionista, "el cine español mantuvo una gran dependencia del extranjero para su propia existencia” (Monterde, 1995, p. 209), ante la necesidad de materia prima, pero también como resultado de la fuerte demanda de cine estadounidense por parte del público. Si atendemos a los datos ofrecidos por el Anuario del Cine Español 1955-1956 publicado por el Sindicato Nacional del Espectáculo (1956, p. 41), del total de filmes estrenados en Madrid (y por extensión, España) entre 1939 y 1954, esto es, 3364, descubriremos que 1518 (45\%) serían de nacionalidad estadounidense, seguidos de 560 títulos españoles (16\%) y 239 mexicanos (7\%).

Como indicábamos, y así han recogido las investigaciones de León (2006b, p. 318), las relaciones comerciales entre la España de Franco y la industria del cine estadounidense fueron "complejas y muy conflictivas, 
aunque el flujo de películas nunca se cortó”, lo cual evidencia improvisación, descoordinación y personalismos que condujeron a una inevitable situación caótica hasta su estabilización en la segunda mitad de la década de los cincuenta.

En este contexto paradójico de desencuentro entre las demandas del mercado y las políticas intervencionistas del régimen (Bosch \& Del Rincón, 1998, p. 118), algunos productores españoles siguen las tendencias estadounidenses de producción de cine estereoscópico. Aunque hemos localizado documentos que ponen de manifiesto la existencia de proyecciones y pruebas con cine estereoscópico en el ámbito de la exhibición desde la década de los veinte en España (Fernández, 2004; Sammons, 1994), no nos consta la nacionalidad española de ninguna de estas cintas.

El primer filme de producción española realizado en técnicas estereoscópicas lleva por título El festival de la tercera dimensión (también titulado El festival de la 3-D), de modo que es dirigido por Luis Torreblanca Ortega y estrenado el 11 de julio de 1953 en el cine Rex de Madrid. El guion está firmado por José López Clemente y la producción corre por parte de Alfredo Talarewitz, fundador y presidente de Filmax, productora de la cinta. La música es obra de Juan Álvarez García y del artista flamenco Niño Ricardo. Fue editada por Ricardo Torres, con dirección de fotografía de Manuel Hernández Sanjuán (especializado en cortos documentales y muy activo entre 1944 y 1982); la autoría de los "efectos especiales" (entendemos que en la filmación estereoscópica) es del propio Talarewitz y de Bill Munn. Se trata de un documental de solo 30 min compuesto por tres piezas que pretenden servirse de la espectacularidad que la técnica permite.

Como compañía fundada ese mismo año, Filmax (con Talarewitz al frente) mostró al abordar la creación de la cinta de Torreblanca una actitud arriesgada e innovadora, dada las pocas garantías de éxito que ofrecía un sistema cuya popularidad creciente no garantizaba su supervivencia más allá de su posible condición de moda pasajera. La falta de continuidad más allá del título referido en la producción 3D de Filmax puede hacernos deducir, o bien la naturaleza puramente experimental y aislada del 
producto, o bien el fracaso de sus expectativas. A pesar de ello, en la década de los sesenta Filmax actuaría como distribuidora de la productora Balcázar, responsable del primer largometraje de ficción tridimensional con parte de producción española en 1967 (Con la muerte a la espalda, Alfonso Balcázar, 1967). Podríamos también intuir una estrategia comercial de posicionamiento por parte de la naciente productora, conclusión a la que llegamos tras observar el cartel del documental, en el que se destaca en un gran tamaño tipográfico "producida por Filmax en España”.

El festival de la tercera dimensión se compone de tres piezas: Al alcance de la mano (demostración de efectos especiales), Desde la barrera (corrida de toros en la plaza de toros de Las Ventas en Madrid con Antoñete) y Baile español (espectáculo coreográfico en el parque de El Retiro de Madrid por parte del ballet de Pilar Monterde). A estos escenarios la base de datos del Ministerio de Cultura suma los merenderos del río Manzanares. Podríamos destacar en cuanto a su contenido el hecho de que a través de un procedimiento cinematográfico novedoso se repiten los mismos motivos que ocuparon las primeras filmaciones realizadas en España por parte tanto de los enviados de los Lumière como por otros operadores: bailes tradicionales y corridas de toros. Intencionado o no, puede resultar cuanto menos sorprendente la frecuencia con que se acude a iconos llenos de tipismo a la hora de abordar una tecnología pionera para el espectáculo.

Una percepción similar, por la relación con los pioneros del cine, es recogida por los comentarios en prensa al estreno de la cinta. Así, el 12 de julio de 1953, un cronista de $A B C$ de Madrid que firma como "Donald" señala que "en el fondo, tiene el mismo carácter de ensayo que en tiempos tuvieron aquellas primeras imágenes en movimiento sobre una pantalla que mostraban la llegada de un tren a una estación o la salida de los obreros de una fábrica". El periodista añade que poco aporta el relieve al cinematógrafo y destaca lo incómodo de las gafas $(A B C, 1953$, p. 45).

En el momento del estreno del filme de Torreblanca Ortega, el 11 julio de 1953, en el cine Rex, como ya anotamos, el espectador de Madrid ya ha conocido al menos un título tridimensional en color previo, Bwana, 
diablo de la selva (Bwana Devil, Arch Oboler, 1952), estrenado el 25 de mayo de 1953. Sin embargo, si atendemos a la cartelera cinematográfica de $A B C$ de Madrid del 12 de julio de 1953 ( $A B C, 1953$, p. 46), veremos que aparece como único título proyectado en el cine Rex, indicándose que se trata de una sesión continua "desde las 11 de la mañana", por lo que no fue programado en sesiones conjuntas con el título español.

Según recoge Méndez en su historia del cine español, El festival de la tercera dimensión fue realizado a partir del procedimiento stereotechnique por parte de técnicos británicos desplazados a España (1965, p. 126). Méndez cita como especialista en la materia a Godfrey Jenniton. Consta, sin embargo, en la ficha del Instituto de la Cinematografía y de las Artes Audiovisuales (ICAA) como director de fotografía Manuel Hernández Sanjuán y como responsables de los efectos especiales aparecen Bill Munn y Talarewitz, como hemos apuntado. El artículo publicado en $A B C$ con motivo del estreno (que creemos fuente de Méndez) recoge igualmente que el procedimiento empleado fue stereotechnique, con equipo y técnicos de procedencia británica. El historiador señala que el resultado no superaba el observado en otros antecedentes extranjeros: "El sistema inglés requiere, como otros en boga, el uso de gafas especiales para que el espectador pueda tener la sensación de las tres dimensiones. En algunos fragmentos de la película se logra el propósito. En otros, no" (p. 126).

El director catalán Francisco Rovira Beleta, iniciado en la cinematografía con Luis Lucia y Juan de Orduña y responsable de algunos títulos de gran éxito comercial en el tardofranquismo, realiza otro experimento de cine tridimensional con El lago de los cisnes (1953), filmación de la interpretación de la obra homónima de Tchaikovsky en Barcelona por parte del Ballet Internacional de Londres. Con una duración de $20 \mathrm{~min}$ (dos rollos), la cinta fue rodada con una cámara dual de $35 \mathrm{~mm}$ de fabricación española en mayo de 1953. Como particularidad técnica, cabría señalar que el procedimiento de filmación en color se realizó en Cinefotocolor, una patente española del color. Joseph María Forn ejercería de ayudante de dirección y director de producción y Antonio López Ballesteros de director de fotografía. 
Salvador Sainz amplía la cuestión acerca de la técnica empleada apuntando que se usaron dos cámaras sincrónicas enfrentadas con un espejo intermedio, que conseguía obtener la distancia binocular entre los objetivos, si bien más adelante se haría con un objetivo doble. Sainz (1990, p. 5) afirma que "el relieve se logró con una inusitada perfección en esta cinta". A juicio de Méndez (1965, pp. 125-126), este experimento español de cine en relieve resultaba aceptable "comparado con otros antecedentes extranjeros".

La edición de La Vanguardia del 14 de junio de 1953 recoge la filmación de la cinta en Barcelona según el procedimiento Natural-Vision, fundado "en la polarización de la luz", requiriendo "dos cámaras para el rodaje y lentes selectivas". El artículo, firmado por Sáenz, cita la participación en la interpretación de Mona Inglesby con el citado Ballet, apuntando al "brillante futuro" que al cine tridimensional le esperaba, "sobre todo en las versiones de obras espectaculares". Rovira Beleta habría acentuado "las conveniencias plásticas del cine tridimensional, todos aquellos pasajes susceptibles de ser vistos de una manera inédita” (Sáenz, 1953, p. 21).

La oferta cinematográfica para el 24 de julio de 1953, también en $\mathrm{La}$ Vanguardia, promociona la exhibición por séptima semana consecutiva del documental musical de Rovira junto con la cinta también estereoscópica El hombre en las tinieblas (Man in the Dark, Lew Landers, 1953), sin ahorrar en adjetivos calificativos al calificarlas como "modelo en su género" e invitando al público a "deleitarse con la maravilla del nuevo procedimiento y el valor indiscutible de las dos películas" (La Vanguardia, 1953, p. 15). El reconocimiento oficial del filme de Rovira Beleta tendría lugar en febrero de 1954 al ser favorecido con un premio del Sindicato Nacional del Espectáculo dentro de la categoría de cortometraje junto con otros dos títulos (ABC, 1954, p. 39).

El resto de la década de los cincuenta no ofrece novedades ni títulos de producción española en el campo que nos ocupa, dado que, de una forma similar al resto de la producción internacional, el fenómeno del cine estereoscópico se diluye rápidamente, ante las dificultades técnicas y el 
cansancio que el visionado de las cintas produce en el espectador. El desinterés de Hollywood por la producción de filmes en formatos estereoscópicos trae parejas, por tanto, la ausencia de nuevos títulos de producción española en relieve.

\section{Segunda fase: largometrajes Hi-Fi Stereo 70 (1967-1969)}

La que hemos denominado segunda fase del cine 3D español es tan breve como la fase anterior, apenas un par de años, si bien esta vez las cintas aumentan su duración hasta llegar a la del largometraje, contando esta vez con una mayor proyección comercial y distribución internacional.

Desde el punto de vista tecnológico, comparten haber sido filmadas mediante el procedimiento Hi-Fi Stereo 70, adaptación de las amplias películas de $70 \mathrm{~mm}$ en la que se toman simultáneamente dos imágenes con formato scope (anamórfico) en un solo negativo (Witte, 2010). La película habrá de ser exhibida con un proyector normal de $70 \mathrm{~mm}$ que contará con una lente especial que permite la adaptación del scope, así como filtros polarizados para crear el efecto tridimensional. El sistema Hi-Fi Stereo 70 permitía además cuatro canales de sonido estéreo. No se trata del único procedimiento de esta naturaleza en este momento, dado que en los Estados Unidos se usa un proceso similar con el sistema StereoVision 70 y en Rusia con el Stereo-70.

En 1967, se prueba el sistema a través de una coproducción con Francia, Italia y Alemania en la que también interviene España. Las productoras implicadas son West Fides, Producciones Cinematográficas Balcázar, Comptoir Français du Film Production (CFFP) e International Germania Film. La coproducción ofrecía en este momento mayores garantías de éxito, ampliando fronteras hacia el comercio exterior y conquistando así nuevas áreas de financiación, si bien terminó por convertirse en un medio de especulación. El título 3D comentado es Con la muerte a la espalda, también titulado Con la morte alle spalle, Typhon Sur Hambourg o Electra One. Dirigido por el prolífico Alfonso Balcázar, contaría con la participación de los actores George Martin (nombre artístico del español Francisco Martínez Celeido), Vivi Bach y Rosalía Neri, conformando parte de un elenco 
interpretativo internacional (propio de las coproducciones, por otra parte) para dar forma a un filme de espionaje que algunos críticos han categorizado como thriller nacional o como el subgénero denominado despectivamente paella-spy. Los interiores fueron rodados en los Estudios Balcázar en Esplugas de Llobregat, en Barcelona, mientras que los exteriores se filmaron en Hamburgo.

En este caso, la trama gira en torno a un ladrón de joyas (George Martin), custodio de una fórmula secreta que supone el antídoto contra una sustancia creada por un científico con una ambición de poder desmedida. Este compuesto anularía la voluntad convirtiendo a los seres humanos en letales asesinos. Tanto el protagonista, un galán seductor dispuesto para la acción en todo momento como la trama de persecución recuerdan los filmes de espionaje de la década (de la serie 007 y del resto de híbridos de procedencia italiana), así como la obra de Hitchcock Con la muerte en los talones (North by Northwest, 1959), a la que remite no solo el título sino también parte de la imaginería promocional, como un cartel en el que el protagonista es perseguido por una avioneta que vuela a muy bajo nivel del suelo. Los valores artísticos o creativos del filme no destacan particularmente y queda como una obra menor, sin pretensiones y limitado presupuesto, de puro entretenimiento. Según la base de datos del ICAA, la cinta tiene una duración de 86 min y sumó 762690 espectadores durante su exhibición en salas.

No tenemos indicios de que la versión tridimensional hubiera llegado a ser estrenada en España, dado que la publicidad de prensa y los comentarios en su estreno no hacen más alusión técnica que a su rodaje en $70 \mathrm{~mm}$ y en color Eastmancolor. Además, el dato presente en la ficha del ICAA de la cinta apunta a su registro en StereoVision en lugar del Hi-Fi Stereo 70. Nos convence del verdadero sistema en que fue filmado la información aportada por Witten (2010) en la que se recogen imágenes procedentes del pressbook del filme, que explica con detalle las bases del Hi-Fi Stereo 70.

La siguiente producción tridimensional de nacionalidad española la supone el filme de Enrique L. Eguiluz para Maxper PC, La marca del hombre lobo (1968), película que inaugura el género patrio del fantaterror con 
la primera de las aventuras de Waldemar Daninsky, personaje interpretado por Paul Naschy en al menos catorce ocasiones. Naschy es responsable igualmente del guion, presentado esta vez como sería habitual en su carrera posterior con su auténtico nombre, Jacinto Molina. A pesar de su reducido presupuesto, la cinta no renuncia a argumentos del fantástico en el que los clásicos del ciclo de terror de la Universal (adaptaciones a su vez de sus referentes literarios del siglo XIX) serían retomados y actualizados a través de nuevos argumentos, enlazando de una forma muy directa con cintas de serie B norteamericanas y británicas filmadas por Roger Corman, así como por la productora Hammer.

La marca del hombre lobo trata la historia de Waldemar, perseguidor de un hombre lobo que acabará convertido en uno de ellos, mezclando sin rubor vampirismo, licantropía e incluso referencias a Frankenstein en la edición norteamericana, en que fue estrenada como Frankenstein's Bloody Terror. El tráiler de la edición norteamericana señala que fue rodada en Super $70 \mathrm{~mm}$ y Chill-o-rama, reclamo comercial sin una base tecnológica real para filmes de terror.

Rodada en diferentes localizaciones de la provincia de Madrid (Colmenar Viejo, Navacerrada, Manzanares El Real, Pelayos de la Presa, Salamanca del Jarama, San Martín de Valdeiglesias), fue estrenada en Valencia y Barcelona en 1968 antes de llegar a ser estrenada en Madrid en 1970. Se filmó mediante el proceso Hi-Fi Stereo 70 (de nuevo la base de datos del ICAA indica $70 \mathrm{~mm}$, color Eastmancolor y "relieve", aunque sin precisar más), solo pudo ser visionada de forma tridimensional en Alemania, los Estados Unidos y Argentina, dado el alto coste del sistema de proyección necesario para este tipo de visionado. La versión exhibida en España alcanzó los 893187 espectadores. La cinta sería premiada en el International Horror Film Festival de Bruselas (Sammons, 1994).

En este caso, el recurso al 3D vuelve a remitir a una de las constantes en las cintas filmadas y exhibidas a través de técnicas estereoscópicas en la cinematografía internacional: el cine de subgénero, en este caso de terror, como género y formato capaz de mantener todavía la atención por parte del espectador aficionado al cine en relieve de una forma tan apasionada 
como desprejuiciada, ante la dudosa calidad cinematográfica de muchas de estas producciones. Los puntos en común son muchos con la posterior Andy Warhol's Frankenstein (1973), dirigida por Paul Morrisey, en 3D y abordando de lleno de nuevo el mito de terror con los personales valores artísticos de Warhol.

El siguiente título de producción tridimensional español, y nos remitimos a Sammons (1994), ofrece mayores dudas acerca de su naturaleza como filme en relieve: Chico, chica, ¡boom! (1969), título dirigido por Juan Bosch para If Producciones, la productora de Ignacio F. Iquino. Sammons (1994, p. 124) señala que solo una fuente fiable apunta al rodaje en técnicas de tridimensionalidad, añadiendo con cierta incertidumbre que "se limitó probablemente a España en lo que se refiere a proyecciones estereoscópicas”. Más allá de esta referencia no hemos hallado ningún otro indicio que confirme la naturaleza estereoscópica de la producción, ni en bibliografía, ni en la base de datos del ICAA, ni en hemerografía del momento.

Otro filme del que surge la duda acerca de su naturaleza tridimensional es 99 mujeres (Jesús Franco, 1969), coproducción entre España (Hesperia Films), Alemania (Corona Filmproduktion) e Italia (Cineproduzioni Associate). Son pocos los fundamentos que justifiquen su filmación tridimensional, si bien Sammons (1994, p. 157) señala que posee todas las características que formalmente potenciarán esta hipótesis: "objetos que salen de la pantalla, profundidad considerable y dedos y palos dirigidos al espectador”. Reseñas más detalladas de las diferentes versiones del filme estrenadas en los países coproductores y en otros mercados no hacen ninguna mención al posible carácter estereoscópico. Según la ficha del ICAA, se trata de una cinta filmada en celuloide de $35 \mathrm{~mm}$ (algo que nos aleja del Hi-Fi Stereo 70), aunque "panorámica" (ignoramos el soporte) y con color Eastmancolor. La edición restaurada editada en Blu-Ray y en 4K en diciembre de 2016 no alude a su posible filmación tridimensional (High-Def Digest, 2016).

\section{Conclusiones}

Las escasas muestras de producción estereoscópica en España responden al perfil de una actividad cinematográfica minoritaria, pero siempre desde la 
renovación del interés comercial internacional por los formatos tridimensionales. De esta forma, como apuntábamos en la hipótesis de partida, podemos concluir que la producción de cine tridimensional en España ha venido motivada por tendencias cinematográficas internacionales destinadas a incrementar la espectacularidad de la experiencia de visionado en salas de cine. La rapidez en la creación de los cortos en 3D de la década de los cincuenta, tanto en el caso de El lago de los cisnes, filmada en mayo de 1953, como en El festival de la tercera dimensión, estrenada apenas dos semanas después del estreno español de Bwana, diablo de la selva, muestran un conocimiento de los productores de la tecnología de producción foránea y una enorme flexibilidad y agilidad a la hora de crear contenidos 3D de producción nacional dentro de nuestras fronteras. Este hecho sugiere un interés tanto por la innovación y la necesidad de renovación tecnológica y de lenguaje como por la comercialidad de las creaciones. Aunque la industria cinematográfica española se encuentra relativamente aislada y distante de la internacional durante la década de los cuarenta y parte de la década de los cincuenta, la actividad de los productores y directores mencionados logra salvar los obstáculos de un régimen político dictatorial y autárquico para adecuarse a los nuevos modelos de producción y de tecnologías, y así adaptarse a las que parecen que son las demandas de la audiencia de cine.

El seguimiento de la producción española de cintas tridimensionales invita a cuestionarse la naturaleza de las relaciones en materia cinematográfica entre la España de Franco y los Estados Unidos. La influencia de la cinematografía estadounidense en su vertiente más tecnológica e industrial no llega a ser el resultado del control de la industria nacional por parte de los estudios de Hollywood: las enormes dificultades que el régimen impone a la importación de películas estadounidenses y las largas negociaciones y la firma de diferentes acuerdos no siempre respetados dan cuenta de unas relaciones tensas e inestables. Ambas partes recelan la una de la otra por cuestiones ideológicas pero también comerciales; la audiencia mantiene la demanda del cine de las majors y ello fortalece a los empresarios (nacionales y a las filiales de aquellas) en sus solicitudes de aperturismo. El mercado y el progresivo cambio de actitud de las instituciones estadounidenses e internacionales con respecto al régimen de Franco terminarán por aca- 
bar con el aislacionismo de la industria cinematográfica española y por regularizar la importación de filmes estadounidenses.

Podríamos concluir que la producción de cine tridimensional español responde antes a la intención de satisfacer una demanda del mercado nacional, más próximo a la realidad de un consumo cotidiano de cine de Hollywood que a una actuación estratégica por parte de la industria cinematográfica estadounidense. Las tempranas muestras de cine estereoscópico nacional no pasan de ser experimentos aislados que no llegaron a consolidar prácticas, de manera paralela a la industria internacional. Apuntemos, en todo caso, que la aceptación de las películas españolas en 3D superó en casos muy concretos a la de otras nacionalidades de mayor tradición y presencia cinematográfica. La potenciación de la filmografía estereoscópica procede de una situación de crisis en la producción tradicional y de la necesidad de crear un nuevo espectáculo que se distancie en primer lugar de la televisión y, décadas después del consumo nacional de contenidos audiovisuales, cualquiera que sea su forma de distribución. Este hecho se repite en nuestros días ante la inestable situación de la industria audiovisual.

El renacer del nuevo cine 3D digital a finales de la primera década del siglo XXI vio aflorar diversos proyectos de nacionalidad española con intención de traspasar las fronteras de nuestro país y explotar ventanas de mercado de difícil acceso a la producción nacional, tanto con títulos de imagen real como con cintas de animación infográfica. En este caso, la producción española pretendió no dejar pasar la oportunidad del que pudo haber sido un momento histórico en la incorporación a una nueva y rentable actividad. La apuesta por una nueva tecnología y un nuevo lenguaje no garantizó el interés permanente del espectador pasada la novedad del sistema, como finalmente ocurrió.

Los intentos históricos en la producción y exhibición estereoscópica no han terminado resultando un fracaso desde el momento en que algunas cintas han logrado un gran éxito comercial, pero la falta de interés posterior de la audiencia ha revelado que el cine estereoscópico ha vuelto a pasar de moda. Las proyecciones en 3D han quedado relegadas a productos 
muy concretos y comerciales de la industria de Hollywood, y su continuidad está favorecida por la adaptación a los estándares de proyección digital y estereoscópica que realizaron las salas cinematográficas entre 2006 y 2016 y a la necesidad de recuperación de la inversión realizada por parte de los exhibidores. El formato tridimensional sirvió, apunta Izquierdo (2012), como impulsor de la digitalización de las salas, con 2011 como punto de inflexión. La versatilidad del proyector digital deja al sector de la exhibición preparado para un uso adaptado a variadas formas de distribución y recepción del producto que será proyectado, pero relega la exhibición 3D a una posición secundaria y auxiliar.

\section{Referencias}

$A B C$ (1953a, julio 12). La primera producción española en relieve, El festival de la tercera dimensión, en el Rex, p. 45.

$A B C$ (1953b, julio 12). Cartelera madrileña, p. 46.

$A B C$ (1954, febrero 2). Anoche se entregaron los premios cinematográficos del Sindicato Nacional del Espectáculo, p. 39.

Bordwell, D., Staiger, J. y Thompson, K. (1996). El cine clásico de Holllywood. Barcelona, España: Paidós.

Bosch, A. \& Del Rincón, M. F. (1998). Franco and Hollywood, 1939-56. New Left Review, 232, 112-127. Recuperado de https://newleftreview.org/issues/I232/articles/aurora-bosch-m-fernanda-del-rincon-franco-and-hollywood-1939-1956

Cánovas Ortega, M. C. (2015). Representaciones femeninas a través del cine musical hollywoodiense en la España de los años 50. Dossiers Feministes, 20, 157-172. Recuperado de http://www.e-revistes.uji. es/index.php/dossiers/article/view/1764

Fernández Rivero, J. A. (2004). Tres dimensiones de la historia de la fotografía: la imagen estereoscópica. Málaga, España: Miramar. 
High-Def Digest. (2016). 99 Women:Director's Cut. Recuperado de http:// bluray.highdefdigest.com/36484/99women.html

Izquierdo Castillo, J. (2012). La digitalización del cine: hacia el desarrollo de un modelo de negocio en internet. En Comunicación y Riesgo: III Congreso Internacional de la Asociación Española de Investigación en Comunicación (pp. 58-59). Tarragona, España: Asociación Española de Investigación en Comunicación.

La Vanguardia (1953, julio 24). Cine en relieve, p. 15.

León Aguinaga, P. (2006a). El comercio cinematográfico como instrumento de la acción norteamericana en España durante la segunda guerra mundial. Cuadernos de Historia Contemporánea, 28, 303-322. Recuperado de http://www.cervantesvirtual.com/nd/ark:/59851/ bmc $447 \mathrm{~m} 9$

León Aguinaga, P. (2006b). El cine norteamericano en España: las negociaciones para su importación, 1950-1955. Hispania: Revista Española de Historia, 222, 277-318. DOI: 10.3989/hispania.2006.v66.i222.9

Méndez Leite, F. (1965). Historia del cine español. Madrid, España: Rialp.

Miguel González, M. (2000). El cine de Hollywood y la censura franquista en la España de los 40: un cine bajo palio. En R. Rabadán (Ed.), Traducción y censura, inglés-español 1939-1985: estudio preliminar (pp. 61-86). León, España: Universidad de León.

Monterde, J.E. (1995). El cine de la autarquía (1939-1950). En Historia del cine español (pp. 181-238). Madrid, España: Cátedra.

Rosendorf, N. M. (2007). 'Hollywood In Madrid': American Film Producers and the Franco Regime, 1950-1970. Historical Journal of Film, Radio and Television, 27(1),77-109.DOI: 10.1080/01439680601177155 
Russo, E. (2012). El 3D una vez más. ¿Esta vez sí? El cine en relieve ante los espectadores contemporáneos. Cuadernos del Centro de Estudios en Diseño y Comunicación. Ensayos, 39, 269-281. Recuperado de http://fido.palermo.edu/servicios_dyc/publicacionesdc/vista/detalle_articulo.php?id_libro=346\&id_articulo=7837

Sáenz Guerrero, H. (1953, junio 14). Los estrenos. Windsor. El lago de los cisnes. La Vanguardia, p. 21.

Sainz, S. (1990). El cine de Rovira-Beleta. Ibiza, España: Semana Internacional del Film de Ibiza.

Sammons, E. (1994). El mundo de las películas tridimensionales. Valencia, España: Filmoteca de la Generalitat Valenciana.

Sindicato Nacional del Espectáculo. (1956). Anuario del Cine Español 1955-1956.

Witte, G. (2010). 3D in the mid 60s in Europe with Hi-Fi Stereo 70. Recuperado de https://web.archive.org/web/20170616012834/http:// www.in70mm.com/news/2010/hifi0/english/index.htm 